\title{
An Analysis of Population Growth Rates Within Typological Categories of Small Southern Cities ${ }^{\dagger}$
}

\author{
William J. Serow, ${ }^{*}$ \\ Julia H. Martin, ${ }^{* *}$ and \\ Michael A. Spar**
}

\section{INTRODUCTION}

Several writers have suggested that the encouragement of small city growth might serve as a partial remedy for the problems of the metropolis by providing an alternate destination point for the migratory population [2;3;5]. A logical precondition for the evaluation and implementation of this suggestion is a body of knowledge derived from data relating to cities of this size class. A review of the social science literature reveals, however, a conspicuous lack of such relevant data. The vast majority of investigations have been concerned with either the metropolis or the village.

The research reported here presents a typology of small cities, as well as an analysis of the causes of population growth within city types. For this research eighty-eight incorporated cities and towns in the South Atlantic and East South Central census divisions were chosen for investigation, all having 1960 populations between 10,000 and 50,000. Places which annexed populations (between 1960 and 1970) amounting to more than two percent of their 1960 population were excluded, since annexation complicates measurement of demographic and economic change. Cities and towns in these two census divisions were selected for several reasons: 1) the South Atlantic and East South Central divisions have generally followed the national trend in small city growth, with the exceptions that between 1950 and 1970 growth rates have exceeded the national average by about 30 percent and have been more nearly equal between 1950-1960 and 1960-1970 than is true nationally; 2) recent migration trends indicate that the role of the South as a net exporter of population is being reversed, and that the South is in the process of becoming an important destination point for migrants from other parts of the United States

\footnotetext{
†This research is supported by grant 1 R01 MH 25484-01 from the Center for Studies of Metropolitan Problems, National Institute of Mental Health

${ }^{*}$ Center for the Study of Population, Florida State University

** Tayloe Murphy Institute, University of Virginia
} 
[21], making this region an exceptionally important one to study with a view toward predicting future trends; 3 ) nevertheless, within the last thirty years the South has come more nearly to resemble other regions in terms of most demographic indices [11].

In order to provide basic information for proposals aimed at stimulating growth in these communities we should recognize that small cities are not necessarily homogenous with respect to economic, social, and demographic characteristics. Consequently, policy applications will vary with the characteristics of the city. In order to provide a middle ground between the consideration of all small cities as a single type and consideration of all small cities as individual units, a factorial typology of small southern cities has been developed.

\section{CITY TYPOLOGIES}

The construction of city typologies has long been of interest to students in several disciplines, including economics, geography, and sociology. In fact the extensive coverage given to the topic of city classification by Hadden and Borgatta [6], Smith [19], and more recently by Kass [9] renders additional summarization superfluous. It is necessary, however, to raise several questions concerning prior work in this area.

Hadden and Borgatta partition city classifications into three broad types: historical classifications, such as those by Mumford [13] and Riemer [17]; functional, or economic specialization classifications, such as those by $\mathrm{Og}$ burn [15], Harris [7], Nelson [14], Atchley [1], and Marshall [10]; and factor analytic classifications, such as those by Price [16], Hofstaetter [8], and Moser and Scott [12]. We will not be concerned with the historical classifications here except to note in passing that their high degree of abstraction makes them of relatively little value for empirical research. The distinction drawn between functional and factor analytic classification schemes is more apparent than real, especially since Kass has successfully merged the two in his recent work.

One point which needs to be made explicit concerns the basic rationale underlying classifications based on functional specialization criteria. Put simply, these classifications assume that functional specialization is the most important city attribute and is systematically related to other social and demographic characteristics of urban populations. Hadden and Borgatta, however, note that:

". . . the economic specialization classifications appear to have only limited utility if one's objective is to predict other characteristics of the city on the basis of economic specialization data or vice versa." (p. 6)

A second major criticism of urban typologies is directed at their practicality. Most functional specialization classifications include so many separate types that any contemplated research based on these typologies is 
foredoomed by the lack of a sufficiently large number of cases within each type. While this problem appears mundane, it is nevertheless true that the generation of a large number of types is intrinsic to most functional classification approaches.

A further tendency in urban research has been the treatment of suburbs as a special and separate, though not necessarily a unitary, class [20]. For example, a possible method for generating a basic categorization of the 88 cities selected for the present study is metropolitan status. Since 33 of the cities lie within the boundaries of Standard Metropolitan Statistical Areas, they qualify as suburbs of central cities. This kind of categorization, however, ignores the fact that suburbs have long been recognized to be of several different types. In particular, Schnore [18] has offered evidence for the existence of three such types: residential suburbs, employing suburbs, and those intermediate between the two. Yet the functional approach to classification suggests that these latter two suburban types may well resemble nonmetropolitan cities with similar industrial configurations in a number of important respects.

The typology constructed for this research is based on a large number of community characteristics in order to avoid the possibility of inadvertantly excluding characteristics which contributed to maximum differentiation. Eighty-seven variables were selected for input, covering a wide array of demographic, social, and economic attributes. The most notable exclusions were population size and climatological indicators: the former because city size is already limited within a narrow range; the climate variables because they may have introduced a geographical bias into the typology.

Distributional transformations were applied to the independent variables in order to maximize the fit of the data to the assumptions underlying the factor analytic approach, as well as to insure bivariate normal distributions, increase homoscedasticity, and eliminate the undue influence of extreme values (outliers). The criteria for judging the relative success of any particular transformation was the degree to which the transformed distribution approximated a normal distribution in terms of skew and kurtosis. Altogether 44 variables were transformed, 34 by a simple $\log _{10}$ computation, five by computing $\log _{10}$ $\left(X_{i}+1\right)$, and four by computing the square root of $\log _{10}\left(X_{i}+1\right) /\left(X_{i}-1\right)$.

The 87 normal and transformed independent variables were factor analyzed with orthogonal (varimax) rotation. This produced 13 multi-variable factors plus 5 single variable factors (after straddling variables had been removed). Variables appearing on each factor are listed in Table 1, along with their respective factor loadings; each factor is briefly described in Figure 1. Variables included in the factors had loadings $\geq \mid .4$.

Factor scales were than computed for those factors containing more than one significant variable (factors 1-13). Each variable was standardized and weighted by the square of its factor loading, with the original sign of the factor loading retained. The weighted values on the particular factor were then summed to yield the factor score. For those factors with only one significant loading, no weight was assigned; the variable was simply standardized. This 
TABLE 1

Factor Loadings, R-type Factor Analysis

\begin{tabular}{|c|c|c|c|c|c|}
\hline Factor & Loading & Variable & Factor & Loading & Variable \\
\hline 1 & -.49 & proportion units rented & 5 & .65 & manufacturing heterogeniety \\
\hline 1 & -.85 & proportion units with no bathroom & 6 & -.49 & housing built 1950-1954 \\
\hline 1 & .73 & proportion units one bathroom & 6 & -.88 & housing built 1940-1949 \\
\hline 1 & -.65 & owned unit value $<\$ 5,000$ & 6 & .44 & housing built before 1940 \\
\hline 1 & .42 & owned unit value $\$ 10,000-\$ 14,000$ & 6 & .66 & housing age heterogeniety \\
\hline 1 & -.69 & rent $<\$ 20$ & 7 & -.75 & proportion one unit rentals \\
\hline 1 & -.86 & rent $\$ 20-\$ 39$ & 7 & .57 & proportion two unit rentals \\
\hline 1 & .52 & rent $\$ 60-\$ 79$ & 7 & .73 & proportion $3-4$ unit rentals \\
\hline 1 & .65 & rent $\$ 80-\$ 99$ & 7 & .62 & proportion $5-9$ unit rentals \\
\hline 1 & .42 & \# highway nodes & 7 & -.56 & median \#rooms, rental units \\
\hline 1 & -.71 & $1.01+$ persons per room, owned units & 7 & -.83 & \# of units-heterogeniety \\
\hline 1 & -.82 & $1.01+$ persons per room, rented units & 7 & .45 & public transportation \\
\hline 1 & -.55 & cumulative fertility, women age 15-24 & 7 & .42 & entertainment workers \\
\hline 1 & -.80 & cumulative fertility, women age $25-34$ & 7 & .72 & export employment \\
\hline 1 & -.75 & cumulative fertility, women age $35-44$ & 7 & 66 & aggregate income \\
\hline 1 & -.44 & proportion walking to work & 8 & .74 & proportion units one + bathroom \\
\hline 1 & -.85 & private household workers & 8 & -.78 & owned unit value $\$ 5,000-\$ 9,999$ \\
\hline 1 & -.53 & furniture manufacturing & 8 & .89 & owned unit value $\$ 20,000-\$ 24,999$ \\
\hline 2 & -.92 & $<.50$ persons per room, owned units & 8 & .83 & owned unit value $\$ 25,000+$ \\
\hline 2 & .90 & $.51-1.0$ persons per room, owned units & 8 & -.59 & rent $\$ 40-\$ 59$ \\
\hline 2 & -.75 & proportion widowed & 8 & .55 & median \# room, owned units \\
\hline 2 & .84 & population per household & 8 & -.46 & male unemployment \\
\hline 2 & .46 & age heterogeniety & 8 & -.59 & female unemployment \\
\hline 2 & .50 & proportion of males in CLF & 8 & .60 & professional workers \\
\hline 2 & -.52 & proportion of male LF age 45 and over & 8 & -.49 & food workers \\
\hline 2 & -.78 & proportion of female LF age 45 and over & 9 & .81 & distance to nearest SMSA \\
\hline 2 & -.50 & personal service workers & 9 & .40 & distance to nearest small city \\
\hline 2 & -.57 & retail workers & 9 & -.73 & \# of SMSAs within 50 miles \\
\hline 3 & -.56 & born different state & 10 & -.60 & government workers \\
\hline 3 & .90 & living in same house & 10 & -.83 & education workers \\
\hline 3 & -.72 & other state 5 yrs ago & 10 & -.82 & proportion never married \\
\hline 3 & -.91 & moved between 1954-1960 & 11 & .64 & per capita city taxes \\
\hline 3 & .82 & moved between 1940-1953 & 11 & .83 & per capita city expenditures \\
\hline 3 & .62 & moved before 1940 & 12 & -.77 & housing unit density \\
\hline 3 & -.41 & educational heterogeniety & 12 & -.79 & population density \\
\hline 3 & -.45 & proportion of LF age 14-17 & 13 & -.77 & welfare workers \\
\hline 3 & -.54 & employment in ag. for. and fish. & 13 & -.56 & communication workers \\
\hline 3 & -.58 & construction employment & 14 & .80 & chemical manufacturing \\
\hline 3 & .53 & manufacturing employment & 15 & -.85 & mining workers \\
\hline 3 & -.54 & year-round vacant units & 16 & .83 & nondurable goods manufacturing \\
\hline 3 & -.71 & housing built $1955-1960$ & 17 & .50 & hospital workers \\
\hline 4 & .83 & proportion of females in CLF & 18 & .37 & primary metal manufacturing \\
\hline 4 & .82 & married women in LF & & & \\
\hline 4 & .80 & females age $45-64$ in LF & & & \\
\hline 4 & .64 & textile and apparel manufacturing & & & \\
\hline 4 & .69 & \#SMSAs within 120 miles & & & \\
\hline 5 & -.75 & transportation workers & & & \\
\hline 5 & -.67 & wholesale workers & & & \\
\hline 6 & -.65 & repair workers & & & \\
\hline 5 & -.65 & food manufacturing & & & \\
\hline
\end{tabular}


FIGURE 1

\section{Summary of Factor Composition}

\begin{tabular}{|c|c|c|c|}
\hline $\begin{array}{l}\text { Factor } \\
\text { Number }\end{array}$ & Description of Factor & Mnemonic & $\begin{array}{l}\text { Number } \\
\text { Variables } \\
\text { Loading }\end{array}$ \\
\hline 1 & Medium-high socioeconomic status & (Med. SES) & 18 \\
\hline 2 & Retirement & (Retire) & 10 \\
\hline 3 & Stability; low socioeconomic status & (Low SES) & 13 \\
\hline 4 & Textile manufacturing & (Textile) & 5 \\
\hline 5 & Goods-moving industries & (Goods Mov.) & 5 \\
\hline 6 & Housing unit age & (Unit Age) & 4 \\
\hline 7 & Urbanization & (Urban) & 10 \\
\hline 8 & High socioeconomic status & (High SES) & 10 \\
\hline 9 & Geographical isolation & (Isolation) & 3 \\
\hline 10 & Educational facilities and government workers & (Ed./Gov.) & 3 \\
\hline 11 & Per capita local government taxes and expenditures & (Taxes) & 2 \\
\hline 12 & Housing and population density & (Pop. Densy.) & 2 \\
\hline 13 & Community service industries & (Serv. Ind.) & 2 \\
\hline 14 & Chemical manufacturing employment & (Chemicals) & 1 \\
\hline 15 & Mining employment & (Mining) & 1 \\
\hline 16 & Nondurable goods manufacturing employment & (Nondurables) & 1 \\
\hline 17 & Hospital employment & (Hospitals) & 1 \\
\hline 18 & Primary metal manufacturing employment & (Metals) & 1 \\
\hline
\end{tabular}

process yielded a data matrix of 18 columns (one column for each factor scale or standardized variable) by 88 rows (one row for each city). Following its construction the factor scale matrix was transposed from a "case-wise" to a "variable-wise" matrix, and this matrix was then factored, again employing varimax rotation.

Five identifiable city groups were generated by the final factor analysis: 1) Deep South cities $(\mathrm{N}=28)$; 2) Industrial cities $(\mathrm{N}=21)$; 3) Coastal Florida (retirement) cities $(\mathrm{N}=18) ; 4)$ "Classical" Suburban cities $(\mathrm{N}=21)$; and 5) Textile and Apparel Manufacturing cities $(\mathrm{N}=17)$. A list of these groupings is presented in Figure 2. All but one of the 88 cities loaded $Z|.30|$ in at least one of these groups. ${ }^{1}$ In order to locate significant differences between these city types and elucidate and verify the factor analytic results, difference-of-means tests were performed between each group on the 18 original factor scales and normalized variables. The results of these tests are presented in Table 2 and Figure 3.

The ability of the 18 factors to differentiate city types varies markedly. Medium and low SES scales differentiated best, in nine of ten comparisons.

\footnotetext{
'Bartow City, Florida did not receive a significant loading on any of the five factors, and was consequently dropped from the analysis.
} 
FIGURE 2

\section{Allocation of Small Southern Cities}

\begin{tabular}{|c|c|c|c|c|c|}
\hline \multicolumn{2}{|l|}{ 1. Deep South } & \multicolumn{2}{|l|}{ 2. Industrial } & \multicolumn{2}{|l|}{ 4. "Classical" Suburbs } \\
\hline Alexander ALA & $.49^{1}$ & ${ }^{* *}$ Fairfield ALA & -.57 & ${ }^{* *}$ Homewood ALA & -.70 \\
\hline Andalusia ALA & .63 & Sheffield ALA & -.34 & ${ }^{* *}$ Coral Gables FLA & -.47 \\
\hline Dothan ALA & .76 & St. Augustine FLA & -.63 & ${ }^{* *}$ N. Miami Beach FLA & -.42 \\
\hline **Phenix ALA & .65 & $* *$ Decatur GA & -.42 & $* *$ North Miami FLA & -.61 \\
\hline Selma ALA & .95 & Cambridge MD & -.51 & ${ }^{* *}$ Miami Springs FLA & -.83 \\
\hline Talladega ALA & .81 & ${ }^{* *}$ Ashland KY & -.73 & ${ }^{* *}$ East Point GA & -.84 \\
\hline Fort Pierce FLA & .43 & Cumberland MD & -.83 & ${ }^{* *}$ Hapeville GA & -.58 \\
\hline Palatka FLA & .79 & ${ }^{* *}$ Newport KY & -.37 & ${ }^{* *}$ Fort Thomas KY & -.63 \\
\hline ** Plant City FLA & .53 & Albemarle NC & -.43 & **Annapolis MD & -.42 \\
\hline$* *$ Sanford FLA & .42 & Elizabethton TENN & -.60 & ${ }^{*}{ }^{*}$ College Park MD & -.70 \\
\hline Bainbridge GA & .83 & Covington VA & -.67 & ${ }^{* *}$ Hyattsville MD & -.65 \\
\hline Carrollton GA & .79 & Pulaski VA & -.52 & $* *$ North Augusta SC & -.70 \\
\hline Lagrange GA & .74 & Suffolk VA & -.59 & ${ }^{* *}$ East Ridge TENN & -.61 \\
\hline Milledgeville GA & .77 & Winchester VA & -.43 & ${ }^{* *}$ Oak Ridge TENN & -.74 \\
\hline Moultrie GA & .87 & Bluefield WVA & -.80 & ${ }^{* *}$ Fairfax VA & -.65 \\
\hline Newnan GA & .85 & Clarksburg WVA & -.92 & ${ }^{* *}$ Falls Church VA & -.54 \\
\hline Thomasville GA & .84 & **Dunbar WVA & -.43 & ${ }^{*}$ Vienna VA & -.64 \\
\hline Waycross GA & .90 & Fairmont WVA & -.91 & Waynesboro VA & -.80 \\
\hline Middlesboro KY & .77 & ${ }^{* *}$ Moundsville WVA & -.72 & ${ }^{*}{ }^{*}$ Dunbar WVA & -.49 \\
\hline Columbus MISS & .81 & Parkersburg WVA & -.66 & ${ }^{*}$ St. Albans WVA & -.68 \\
\hline Corinth MISS & .72 & ${ }^{* *}$ Weirton, WVA & -.48 & ${ }^{* *}$ Weirton WVA & -.72 \\
\hline Laurel MISS & .91 & & & & \\
\hline Meridian MISS & .87 & & & & \\
\hline Natchez MISS & .94 & 3. Coastal Florida & & 5. Textile \& Appare & \\
\hline Vicksburg MISS & .88 & & & Manufacturing & \\
\hline Yazoo City MISS & .86 & ${ }^{* *}$ Boynton Beach FLA & .76 & & \\
\hline Georgetown SC & .71 & Bradenton FLA & .82 & Alexander City ALA & .75 \\
\hline **Petersburg VA & .41 & ${ }^{* *}$ Coral Gables FLA & .70 & Andalusia ALA & .49 \\
\hline & & Deland FLA & .81 & Carrollton GA & .46 \\
\hline & & ${ }^{* *}$ Delray FLA & .79 & Lagrange GA & .47 \\
\hline & & Fort Pierce FLA & .50 & Cambridge MD & .64 \\
\hline & & Key West FLA & .40 & Salisbury MD & .54 \\
\hline & & ${ }^{* *}$ Lake Worth FLA & .87 & Albemarle NC & .85 \\
\hline & & ${ }^{* *}$ North Miami FLA & .49 & ${ }^{* *}$ Monroe $\mathrm{NC}$ & .80 \\
\hline & & ${ }^{* *}$ N. Miami Beach FLA & .69 & Reidsville NC & .93 \\
\hline & & St. Augustine FLA & .65 & Roanoke Rapids NC & .77 \\
\hline & & ${ }^{* *}$ Sanford FLA & .54 & Shelby NC & .89 \\
\hline & & Sarasota FLA & .95 & Statesville NC & .86 \\
\hline & & Winter Haven FLA & .86 & Thomasville NC & .54 \\
\hline & & Salisbury MD & .48 & Athens TENN & .61 \\
\hline & & Fredericksburg VA & .59 & Elizabethton TENN & .44 \\
\hline & & Staunton VA & .40 & Danville VA & .50 \\
\hline & & Winchester VA & .58 & Pulaski VA & .45 \\
\hline
\end{tabular}

'Factor Loadings

** Suburban Cities 
TABLE 2

Mean Values for City Groups, on 18 Factor Scales

\begin{tabular}{|c|c|c|c|c|c|c|}
\hline \multirow[b]{2}{*}{ Factor Scales } & \multicolumn{6}{|c|}{ City Groups } \\
\hline & $\begin{array}{l}\# 1 \\
\text { (Deep } \\
\text { South) }\end{array}$ & $\begin{array}{c}\# 2 \\
\text { (Industrial) }\end{array}$ & $\begin{array}{c}\# 3 \\
\text { (Coastal } \\
\text { Florida) }\end{array}$ & $\begin{array}{c}\# 4 \\
\text { ("Classical" } \\
\text { Suburbs) }\end{array}$ & $\begin{array}{c}\# 5 \\
\text { (Textiles) }\end{array}$ & $\begin{array}{l}\text { Group } \\
\text { Mean }\end{array}$ \\
\hline I (Med. SES) & -7.38 & 2.96 & 2.92 & 6.64 & -1.35 & .76 \\
\hline 2 (Retire) & .18 & 1.35 & 3.39 & -3.38 & -.40 & .23 \\
\hline 3 (Low SES) & .21 & 3.88 & -4.20 & -1.33 & 2.34 & .18 \\
\hline 4 (Textiles) & 1.15 & -1.30 & -1.03 & -1.37 & 2.93 & .08 \\
\hline 5 (Goods Mov.) & .19 & .04 & -.05 & .12 & -.62 & -.06 \\
\hline 6 (Unit Age) & -.01 & 1.25 & -.21 & -1.08 & -.00 & -.01 \\
\hline 7 (Urban) & -.85 & -.07 & 1.70 & 1.53 & -2.25 & .01 \\
\hline 8 (High SES) & -1.51 & -1.53 & 1.93 & 3.86 & -2.27 & .10 \\
\hline 9 (Isolation) & .46 & .34 & -.16 & -.85 & -.11 & -.06 \\
\hline 10 (Ed./Gov.) & .15 & -.42 & .17 & .23 & -.43 & -.06 \\
\hline 11 (Taxes) & -.34 & .09 & .75 & -.11 & -.14 & .05 \\
\hline 12 (Pop. Densy.) & -3.64 & -2.19 & -2.40 & -2.67 & -3.52 & -2.88 \\
\hline 13 (Serv. Ind.) & -.15 & -.02 & -.08 & .25 & -.40 & -.05 \\
\hline 14 (Chemicals) & -.24 & .21 & .09 & .26 & -.52 & -.04 \\
\hline 15 (Mining) & .26 & .29 & -.19 & -.23 & -.19 & .02 \\
\hline 16 (Nondurables) & .10 & -.08 & -.33 & -.13 & -.35 & -.16 \\
\hline 17 (Hospitals) & .04 & .38 & .13 & -.46 & -.12 & -.01 \\
\hline 18 (Metals) & .26 & .56 & -.07 & .21 & -.26 & .04 \\
\hline
\end{tabular}

Textiles, unit age, and urban differentiate seven pairs. Mean retirement scores and population density scores are significantly different in six comparisons, high SES scores in five comparisons, and education-government employment, taxes-expenditures, and isolation in three comparisons. The remaining factors differentiated city groups in only zero to two comparisons. ${ }^{2}$

The results of the difference-of-means tests indicates that the city types comprise groups which differ significantly. The number of significant differences between city pair groups ranged from four to 11 of the 18 factor scales; the mean number of differences was 7.4. In addition these results lend strong empirical support to Schnore's contention [18] that suburban cities do not constitute an homogenous set. It is evident from Figure 2 that while many cities lying within SMSA boundaries turn up as a separate type ("Classical" Suburbs), nevertheless many are also included in groups 2 (Industrial cities)

\footnotetext{
'It should be noted that those scales which differentiated best are not only multi-variable but also multidimensional scales. Medium SES, for example, is a scale composed of various housing measures, percent of the employed who walk to work, three fertility measures, two industrial measures, and a geographical measure, while both of the factors which failed to differentiate at all are single-variable measures. In fact, among the scales which differentiated successfully in five or more instances the mean number of variables was nine, while among those which differentiated zero to three times (none differentiated four times) the mean number of variables was two.
} 
FIGURE 3

Difference-of-Means Tests, Pairs of City Groups, on 18 Factor Scales

\begin{tabular}{lcccccccccccc}
\hline & \multicolumn{10}{c}{ Pairs of City Groups } \\
\cline { 2 - 10 } Factor Scales & $1 \& 2$ & $1 \& 3$ & $1 \& 4$ & $1 \& 5$ & $2 \& 3$ & $2 \& 4$ & $2 \& 5$ & $3 \& 4$ & $3 \& 5$ & $4 \& 5$ & Total $^{\text {a }}$ \\
\hline 1 (Med. SES) & $\mathrm{X}$ & $\mathrm{X}$ & $\mathrm{X}$ & $\mathrm{X}$ & & $\mathrm{X}$ & $\mathrm{X}$ & $\mathrm{X}$ & $\mathrm{X}$ & $\mathrm{X}$ & 9 \\
2 (Retire) & & $\mathrm{X}$ & $\mathrm{X}$ & & & $\mathrm{X}$ & & $\mathrm{X}$ & $\mathrm{X}$ & $\mathrm{X}$ & 6 \\
3 (Low SES) & $\mathrm{X}$ & $\mathrm{X}$ & & $\mathrm{X}$ & $\mathrm{X}$ & $\mathrm{X}$ & $\mathrm{X}$ & $\mathrm{X}$ & $\mathrm{X}$ & $\mathrm{X}$ & 9 \\
4 (Textiles) & $\mathrm{X}$ & $\mathrm{X}$ & $\mathrm{X}$ & $\mathrm{X}$ & & & $\mathrm{X}$ & & $\mathrm{X}$ & $\mathrm{X}$ & 7 \\
5 (Goods Mov.) & & & & $\mathrm{X}$ & & & & & & & 1 \\
6 (Unit Age) & $\mathrm{X}$ & & $\mathrm{X}$ & & $\mathrm{X}$ & $\mathrm{X}$ & $\mathrm{X}$ & $\mathrm{X}$ & & $\mathrm{X}$ & 7 \\
7 (Urban) & & $\mathrm{X}$ & $\mathrm{X}$ & $\mathrm{X}$ & $\mathrm{X}$ & & $\mathrm{X}$ & & $\mathrm{X}$ & $\mathrm{X}$ & 7 \\
8 (High SES) & & $\mathrm{X}$ & $\mathrm{X}$ & & & $\mathrm{X}$ & & & $\mathrm{X}$ & $\mathrm{X}$ & 5 \\
9 (Isolation) & & & $\mathrm{X}$ & & & $\mathrm{X}$ & & & & $\mathrm{X}$ & 3 \\
10 (Ed./Gov.) & $\mathrm{X}$ & & & $\mathrm{X}$ & $\mathrm{X}$ & & & & & & 3 \\
11 & (Taxes) & & $\mathrm{X}$ & & & & & & $\mathrm{X}$ & $\mathrm{X}$ & & 3 \\
12 (Pop. Densy.) & $\mathrm{X}$ & $\mathrm{X}$ & $\mathrm{X}$ & & & & $\mathrm{X}$ & & $\mathrm{X}$ & $\mathrm{X}$ & 6 \\
13 (Servc. Ind.) & & & & & & & & & & $\mathrm{X}$ & 1 \\
14 (Chemicals) & & & & & & & $\mathrm{X}$ & & & $\mathrm{X}$ & 2 \\
15 (Mining) & & & $\mathrm{X}$ & $\mathrm{X}$ & & & & & & & 2 \\
16 (Nondurables) & & & & & & & & & & & 0 \\
17 (Hospitals) & & & & & & $\mathrm{X}$ & & & & & 1 \\
18 (Metals) & $\mathrm{X}$ & & & & & & $\mathrm{X}$ & & & & 2 \\
Total & 7 & 8 & 9 & 7 & 4 & 7 & 8 & 5 & 8 & 11 & 74 \\
\hline
\end{tabular}

An " $\mathrm{X}$ " in a cell indicates the appropriate mean value differs significantly between the two groups (.05 level, two tailed test).

${ }^{a}$ Number of city group pairs differentiated by the particular factor (maximum is 10 per scale).

${ }^{b}$ Number of factor scales differentiating the particular city group pair (maximum is 18 per pair).

and 3 (Coastal Florida cities). It is equally evident that nonmetropolitan cities are not uniform. In the following sections we present a summary of the characteristics of each city type.

\section{Group 1. Deep South Cities}

The deep south character of these cities is immediately apparent: six of the eight Alabama cities included in the research are in this group, eight of the 11 Georgia cities, and all seven of the Mississippi cities; these constitute 21 out of the 28 cities in Group 1. These cities are notable for their extremely low scores on medium SES and taxes-and-expenditures, combined with relatively low scores on low SES-stagnation and population density. Their populations tend to be younger than those of Coastal Florida cities but older than those of Suburban cities. Housing units in these cities are of about the same age as those in Coastal Florida cities and Textile and Apparel Manufacturing cities; however, they are newer than Industrial cities and older than "Classical" 
Suburban cities. In terms of urbanization, these Deep South cities are less urbanized than Coastal Florida or "Classical" Suburban cities, more urbanized than the Textile and Apparel Manufacturing cities, and about as urbanized as the Industrial cities.

\section{Group 2. Industrial Cities}

The geographical identity of the cities included in Group 2 is somewhat less clear than that of the previous group. Seven of the eight West Virginia cities loaded significantly on this factor together with a scattering of cities from other states. The group is most obviously distinguished from others by its scores on the housing unit age and low SES factors: it is significantly higher on the first of these than all other cities except Textile and Apparel cities. Group 2 cities are less urbanized than Coastal Florida or "Classical" Suburban cities. Of the three equally urbanized groups, however, Group 2 shows the highest population density.

\section{Group 3. Coastal Florida Cities}

Of the 18 cities in Group 3,14 are located in Florida, in the main along the eastern coast. These cities score extremely low on the low SES factor; in fact the mean score of this group is significantly lower than that of every other group along this dimension. In addition, four other factors differentiate Group 3 cities. In terms of per capita taxes and expenditures and of retirement they are higher than Groups 1, 4, and 5 but not significantly different from Group 2. In terms of urbanization they are higher than Groups 1, 2, and 5 but not significantly different from Group 4, the suburbs. Finally, Group 3 cities score higher on medium SES than Groups 1 and 5 and lower than Group 4, while again they resemble Group 2 in this regard. In general, Coastal Florida cities are distinguished from other groups by a very low mean score on low SES and a very high score on urbanization.

\section{Group 4. "Classical" Suburban Cities}

Cities in Group 4 are well differentiated from other cities, scoring significantly higher on medium SES and significantly lower on retirement and housing unit age than each of the other groups. In addition, Group 4 cities score significantly higher on high SES and urbanization than do Deep South, Industrial, and Textile and Apparel Manufacturing cities, though they resemble Coastal Florida cities in both these respects. On low SES "Classical" Suburban cities display a mixed pattern: they score lower than Group 2 and 5 cities but higher than Group 3 cities and are most similar to Group 1 on this dimension. Finally, although the geographical isolation dimension is not a particularly important one in differentiating most groups, it should be noted that the cities of Group 4 score the lowest of all groups on this factor, significantly lower than either Group 1 or Group 5. These cities are notable, therefore, for 
their extremely low scores on retirement, housing unit age, and isolation, a pattern to be expected for suburban cities.

\section{Group 5. Textile and Apparel Manufacturing Cities}

Together with other cities in the Middle South, all seven of the North Carolina cities load significantly in Group 5. The difference-between-themeans tests indicate a pattern of low socioeconomic status for these cities. Although they score higher on medium SES than do Group 1 cities, their scores on this factor are significantly lower than those of Group 2, 3, and 4 cities; similarly, although they resemble Group 2 on low SES, they show significantly higher scores on this factor than Groups 1, 3, and 4. On the high SES factor Textile and Apparel Manufacturing cities score the lowest of all groups, although the differences are significant only in relation to Groups 3 and 4 . In addition, three other dimensions are important in differentiating the cities in Group 5 from those in other groups. First, they score significantly higher on the textiles and apparel factor than all other groups; second, they are equally as urbanized as Group 2 cities but less urbanized than Groups 1, 3, and 4; and last, they have lower population densities than Industrial, Coastal Florida, or "Classical" Suburban cities. These cities are notable, therefore, for their very low scores on urbanization, high SES, and population density and for their high scores on low SES and textiles and apparels.

\section{ANALYSIS OF POPULATION GROWTH RATES}

The preceding analysis has shown that the city groups are well differentiated in terms of the 18 factor scales used in their construction. Further, the internal composition of each city group has a certain "face validity." As a further empirical test of the adequacy of the typology we present an analysis of population growth rates within each city type. If this analysis confirms previous findings relating city growth with migration and changes in employment, this will serve to indicate the utility of the typology for other types of analyses.

In order to investigate the antecedents of population change in small cities we have constructed an ecological model of city growth and estimated parameters for the model with data for the cities in each of the five types previously described. In each case the model is the same, although differences between types become manifest since the fitted models include only significant path coefficients. The general model includes eleven exogenous variables, three intermediate variables, and the endogenous variable. The eleven exogenous variables refer to characteristics of the city, or of the aggregate city population, as of 1960. These include: (1) BLACK POPULATION, defined as the percent of the city population nonwhite; (2) CITY SIZE, the enumerated population of the city on April 1, 1960; (3) BASE RATIO, the percent of the labor force engaged in producing goods or services for nonlocal consumption; (4) UNEMPLOYMENT, the percent of the male civilian labor 
force unemployed; (5) P.C. EXPENDITURES, defined as per capita city expenditures for FY 1962; (6) MEDIAN FAMILY INCOME, defined by the Bureau of the Census and referring to income earned in 1959; (7) CLIMATE, the average annual winter maximum daily temperature between 1950 and 1960; (8) HIGHWAYS, the number of major highways within a fifteen mile radius of the city; (9) HIGHWAY NODES, the number of intersections of major highways within a fifteen mile radius of the city; (10) COLLEGES, the number of institutions of higher education located in the city; (11) SMSA DISTANCE, the straight line distance, in miles, to the nearest Standard Metropolitan Statistical Area. The three intermediate variables include: (1) NET MIGRATION, calculated by the residual method for the period between April 1, 1960 and April 1, 1970; (2) LABOR FORCE CHANGE, defined as net change in the total labor force between April 1, 1960 and April 1, 1970; (3) MANUFACTURING CHANGE, defined as net change in the number of manufacturing workers between April 1, 1960 and April 1, 1970. The endogenous variable POPULATION CHANGE is defined as the decennial rate of population change between April 1, 1960 and April 1, 1970, controlling for population gained through annexation.

In the construction of the path models all variables were temporally ordered. The eleven exogenous variables are considered to act simultaneously, and precede the intermediate and endogenous variables. The three intermediate variables were time-ordered so that MANUFACTURING CHANGE precedes LABOR FORCE CHANGE, which precedes NET MIGRATION. The endogenous variable POPULATION CHANGE is the last variable in the sequence. The rationale behind the ordering of the intermediate variables is predicated on the following implicit relationships: first, it is assumed that the level of net migration is dependent on changes in employment opportunities, as measured by both LABOR FORCE CHANGE and MANUFACTURING CHANGE: second, it is assumed that LABOR FORCE CHANGE is dependent on MANUFACTURING CHANGE. Two reasons underlie this assumption. First, manufacturing employment is generally regarded by economicbase theorists as influencing the development of supporting, or service, industries. Second, the two variables are not mutually exclusive, in that the measurement of LABOR FORCE CHANGE includes changes in manufacturing employment. If the number of manufacturing workers increases, at least one component of the total labor force will also increase. The reverse condition is not logically implied, however, since the total labor force may increase with no necessary effect on manufacturing employment.

Path models for each city type are presented in Figures 4 through 8 . These employ the conventional nomenclature for such models; coefficients assigned to single-headed arrows are standardized regression coefficients (beta coefficients), while coefficients associated with double-headed arrows (those between the exogenous variables) are zero-order correlation coefficients. Each intermediate variable, as well as the endogenous variable, is associated with a residual variable. The magnitude of this residual term is equal to the square 


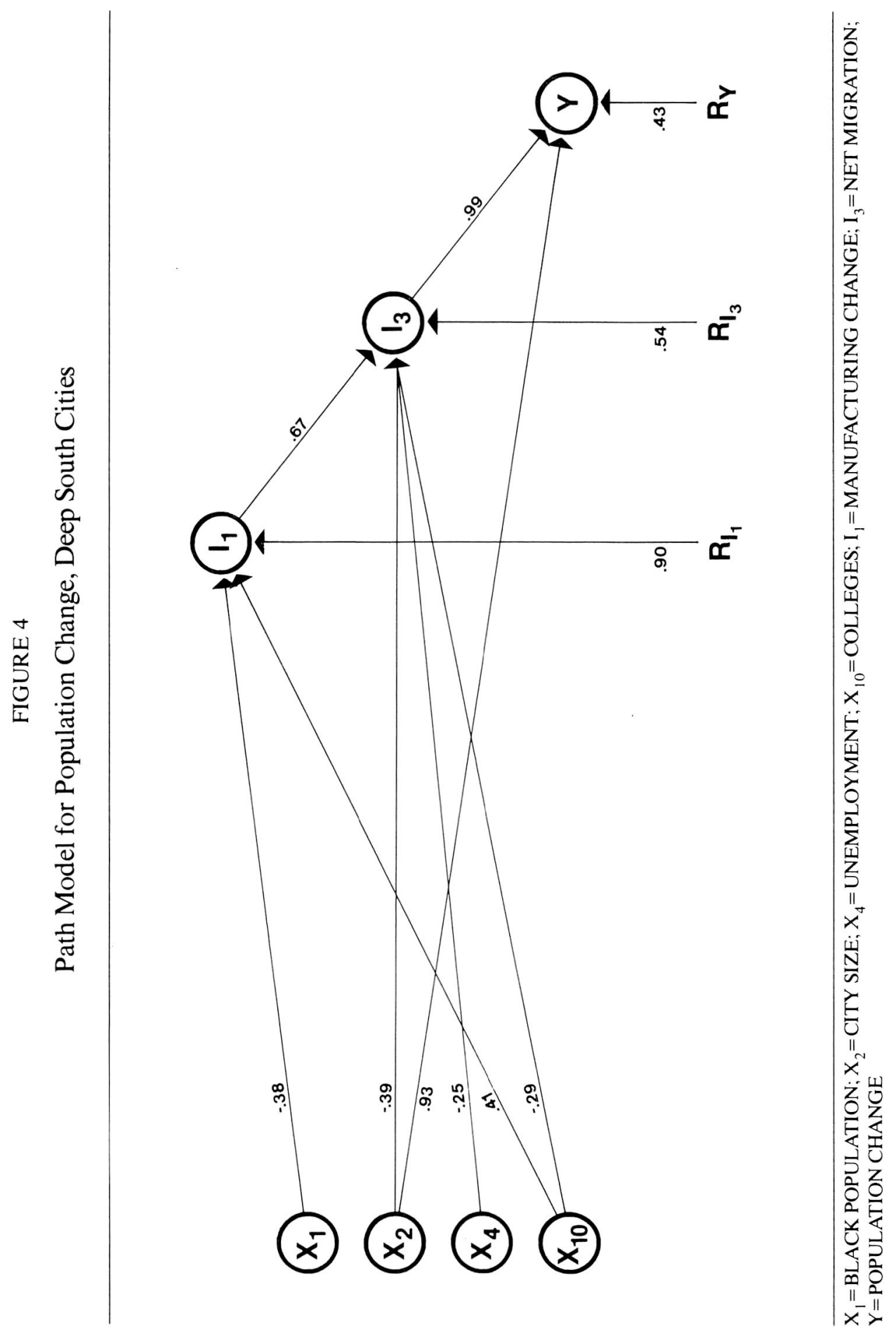



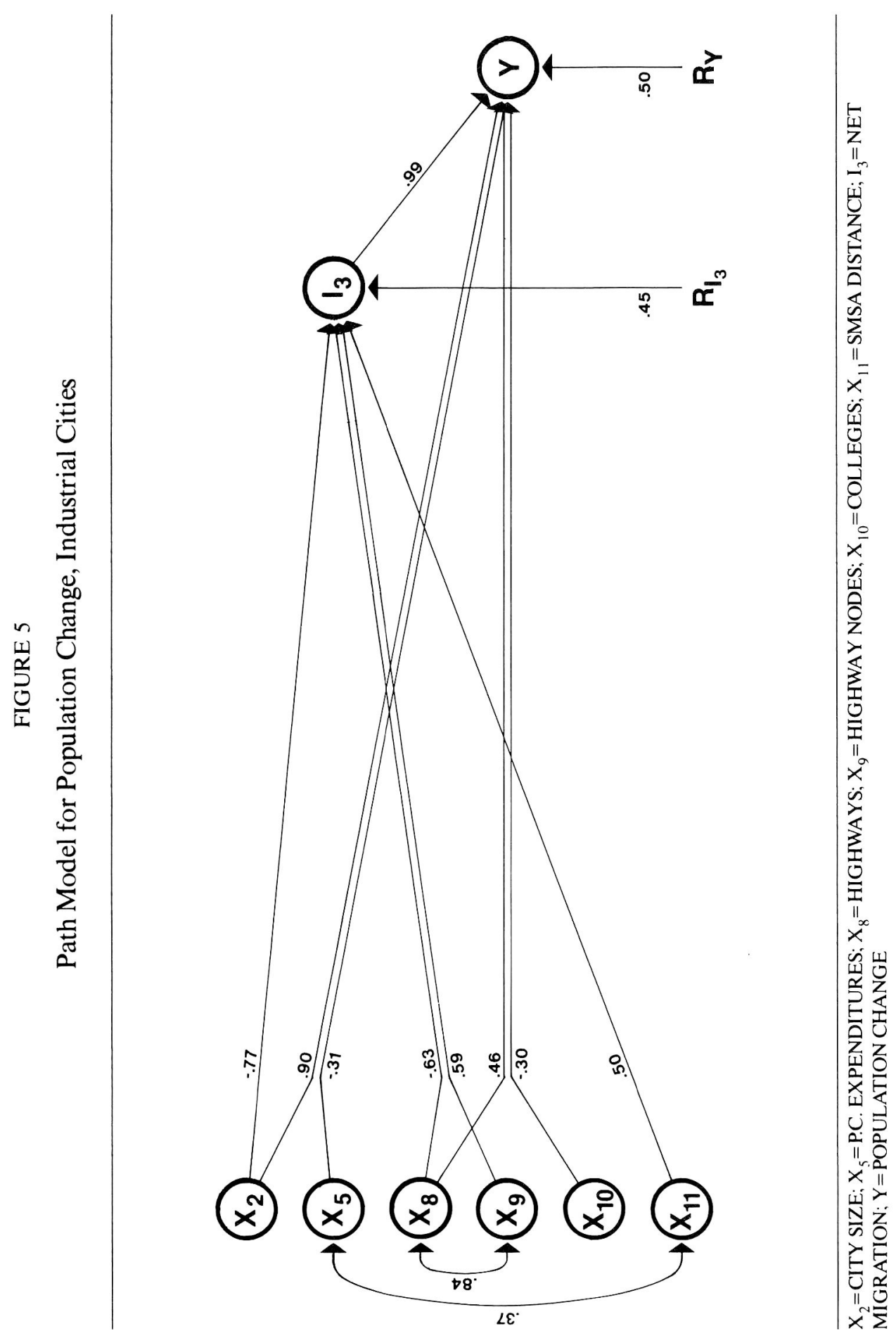
FIGURE 6

Path Model for Population Change, Coastal Florida Cities

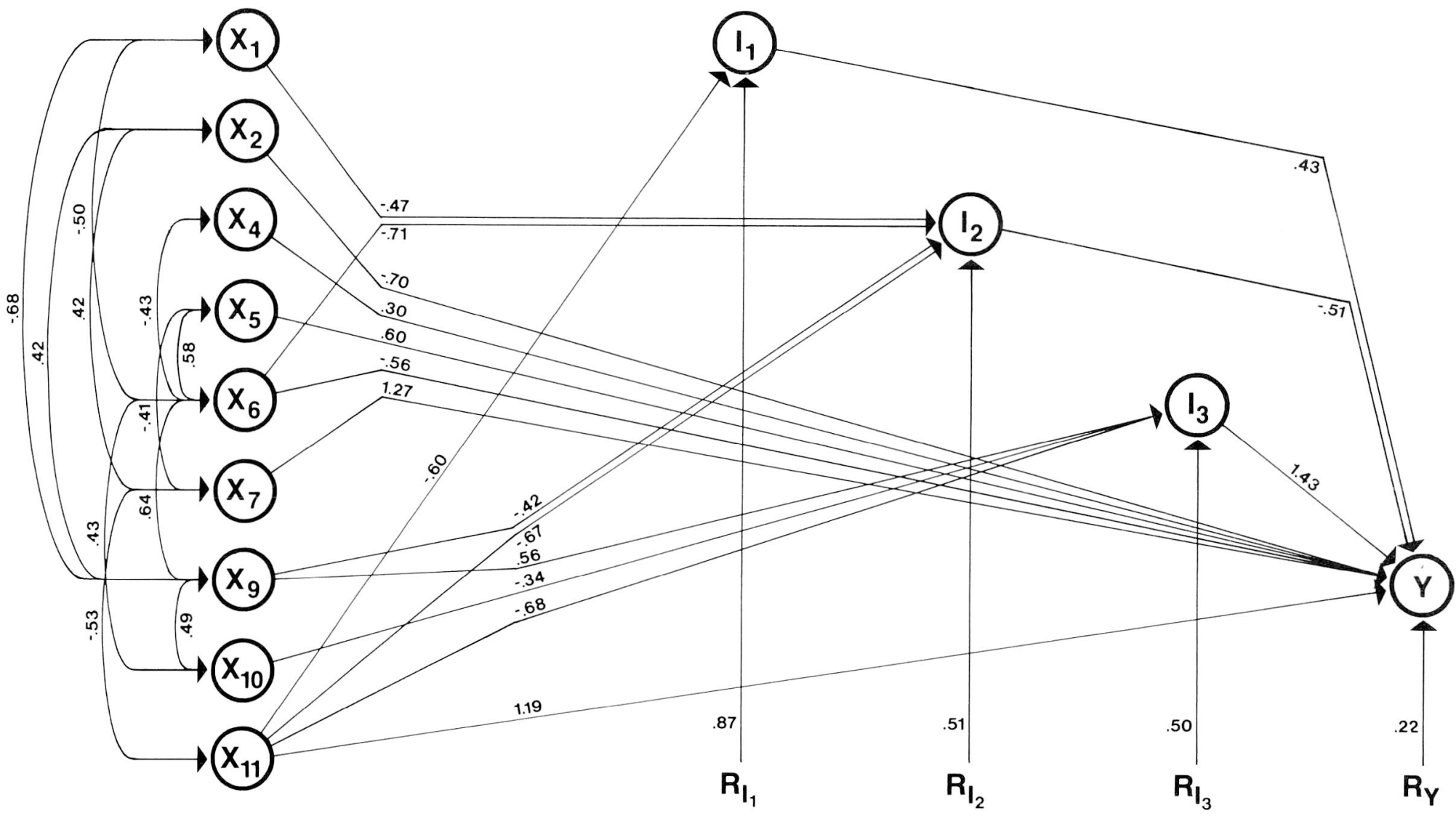

$\mathrm{X}_{1}=$ BLACK POPULATION; $\mathrm{X}_{2}=$ CITY SIZE; $\mathrm{X}_{4}=$ UNEMPLOYMENT; $\mathrm{X}_{5}=$ P.C. EXPENDITURES; $\mathrm{X}_{6}=$ MEDIAN FAMILY INCOME; $\mathrm{X}_{7}=\mathrm{CLIMATE}$; $\mathrm{X}_{9}=$ HIGHWAY NODES; $\mathrm{X}_{10}=$ COLLEGES; $\mathrm{X}_{11}=$ SMSA DISTANCE; $\mathrm{I}_{1}=$ MANUFACTURING CHANGE; $\mathrm{I}_{2}=$ LABOR FORCE CHANGE; $\mathrm{I}_{3}=$ NET MIGRATION; $Y=$ POPULATION CHANGE 


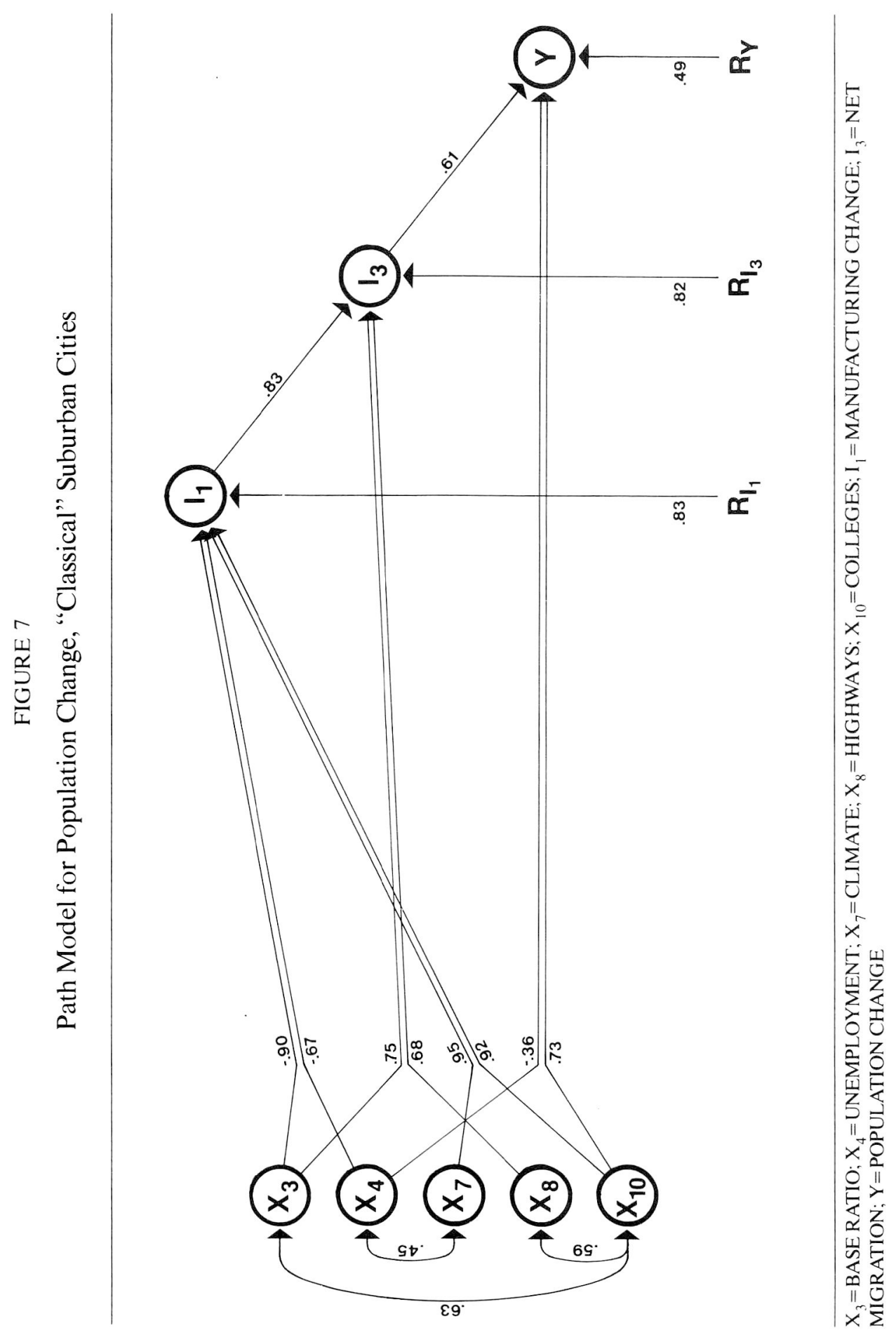




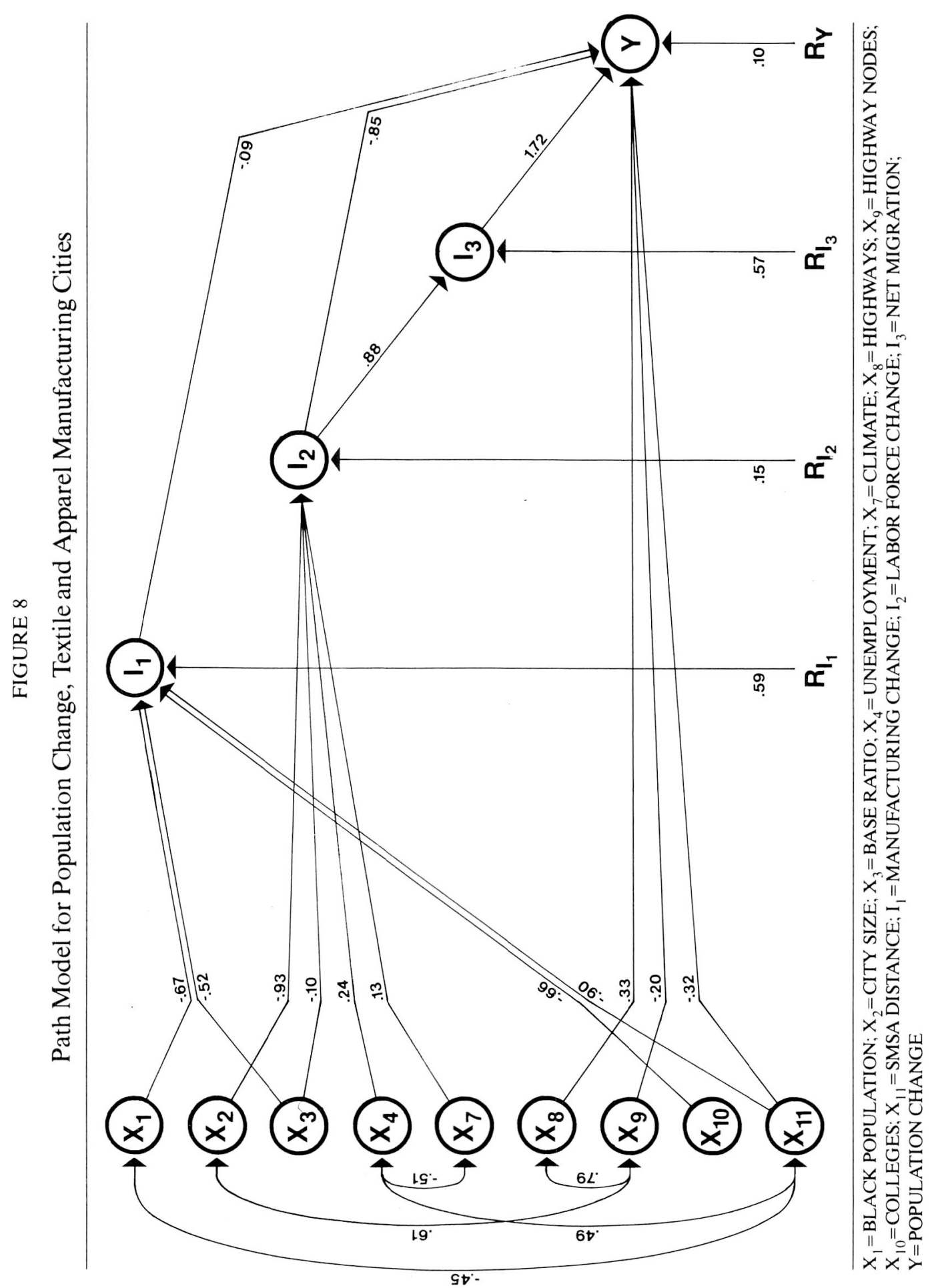


root of one minus the coefficient of determination. The residual indicates the proportion of variance in the variable not accounted for by those variables on which it is causally dependent.

Inspection of Figures 4 through 8 indicates some important properties of city growth. First, it may be noted that the level of net migration is an important determinant of decennial growth rates in each city type. While this result is in no way surprising, considering that migration is a component of population growth, these data make it possible to gauge the precise magnitude of its impact. Since beta coefficients represent proportionate change in the dependent variable, given a one standard deviation unit change in the independent variable, we can calculate the actual impact for a predetermined level of change in the independent variable. In the case of net migration these calculations reveal that an increase in the decennial level of net migration by 100 will correspond to an increase in the decennial growth rate of 0.38 percent for cities in the Deep South group, 0.44 percent for Industrial cities, 0.64 percent for Coastal Florida cities, 0.25 percent for "Classical" Suburban cities, and 0.97 percent for Textile and Apparel Manufacturing cities. These differences reflect the degree to which the growth rate depends on net migration, rather than natural increase. "Classical" Suburban cities, because of the age structure of their populations, tend to depend less on net migration as a source of population growth than other city groups, while Textile and Apparel Manufacturing cities depend most on net migration, a fact undoubtedly related to the high levels of female employment in textile industries, and concomitant reductions in fertility. The generally negative relationship between female labor force participants and fertility is well established [22].

A second point which should be noted is the adequacy of the models in predicting the level of net migration. Coefficients of determination $\left(R^{2}\right)$ for net migration are generally high, .71 for Deep South cities, .80 for Industrial cities, .75 for Coastal Florida cities, .33 for "Classical" Suburban cities, and .68 for Textile and Apparel Manufacturing cities. The low $\mathrm{R}^{2}$ value for the suburban city group indicates that the general model is deficient in this case, and should be expanded to include characteristics of the metropolitan center.

Given the significant impact of net migration on population growth, it is appropriate to inquire into the determinants of the level of net migration. Of special importance here is the effect of the other two intermediate variables, net change in the total labor force (LABOR FORCE CHANGE) and net change in manufacturing employment (MANUFACTURING CHANGE). In the Deep South city group MANUFACTURING CHANGE is directly associated with NET MIGRATION, and a net increase of 100 manufacturing workers produces a net increase of 610 migrants. In the "Classical" Suburban city cluster NET MIGRATION is also directly dependent on MANUFACTURING CHANGE, a net increase of 100 manufacturing workers being associated with an increase of 1,049 migrants. In the Textile and Apparel Manufacturing city cluster NET MIGRATION is directly dependent on LABOR FORCE CHANGE, with the result that a net increase of 100 
workers to the labor force produces a net increase of 106 migrants. In the two remaining city groups (Industrial and Coastal Florida) change in the total labor force or in manufacturing employment is not associated with changes in the level of net migration. It should be noted, however, that both LABOR FORCE CHANGE and MANUFACTURING CHANGE are directly related to changes in the decennial growth rate for Coastal Florida cities (Figure 6).

While it is possible, given the path models, to trace still further back in order to determine the influence of the exogenous variables on the level of net migration, such an analysis is prevented by limitations of space.

\section{SUMMARY AND CONCLUSIONS}

This paper has reported the results of a factor-analytic typology of small southern cities, as well as providing a preliminary analysis, via path models, of the determinants of the rate of population growth and the level of net migration within the constructed city types.

Several advantages of this typology may be enumerated: 1) relatively few categories (five) were generated, preserving a relatively high number of cases within each type; 2) the typological categories were shown by statistical means to differ from each other in a number of significant ways; 3 ) the categories are recognizable and easily amenable to interpretation; 4) students interested in the case study approach have, in the factor loadings, an empirical justification for selecting the most representative city from each category. The major drawback of the typology lies in the fact that the categories are not mutually exclusive.

The typology clearly indicates that small southern cities are not homogenous and provides support for the contention that industrial suburbs resemble independent small cities in several respects. It may be further noted that of the five city types generated, only two are exclusively functional, Textile and Apparel Manufacturing and Industrial cities. This research thus suggest that the limitation of typological criteria to functional specialization input variables may produce misleading results by ignoring other important community dimensions which are not strongly associated with functional specialization.

To demonstrate the utility of the typological approach path models were constructed for each city class, using the decennial rate of population growth as the endogenous variable, and net migration and employment changes as intermediate variables. This analysis pointed out that while the level of net migration was an important component of population growth in each of the five city types, there were also considerable differences in the magnitude of this impact, differences which were attributable, on an ex post facto basis, to the nature of the city types. A second important result of the analysis was the finding that gains in employment were not linked with increases in the level of net migration for either Industrial or Coastal Florida cities. 


\section{REFERENCES}

1. Atchley, Robert C. "A Size-Function Typology of Cities," Demography, 4 (1967), pp. 721-33.

2. Clawson, Marion. "The Future of Nonmetropolitan America," The American Scholar, 4 (1972), pp. 102-09.

3. Commission on Population Growth and the American Future. Population and the American Future. Washington: Government Printing Office, 1972.

4. Duncan, Otis Dudley, W. Richard Scott, Stanley Lieberson, Beverly Duncan, Hal H. Winsborough. Metropolis and Region. Baltimore: John Hopkins Press, 1960.

5. Fuguitt, Glenn V. "The Places Left Behind: Population Trends and Policy for Rural America," Rural Sociology, 36 (1971), pp. 449-70.

6. Hadden, Jeffrey K., and E. F. Borgatta. American Cities. New York: Rand McNally, 1965.

7. Harris, Chauncy D. "A Functional Classification of Cities in the United States," Geographical Review, 33 (1943), pp. 86-99.

8. Hofstaetter, Peter R. "Your City-Revisited: A Factorial Study of Cultural Patterns," American Catholic Sociological Review, 13 (1952), pp. 159-68.

9. Kass, Roy. "A Functional Classification of Metropolitan Communities," Demography, 10 (1973), pp. 427-45.

10. Marshall, John U. "City Size, Economic Diversity, and Functional Type: The Canadian Case," Economic Geography, 51 (1975), pp. 37-49.

11. McKinney, John C. and Linda Brookover Bourque. "The Changing South: National In- corporation of a Region," American Sociological Review 36 (1971), pp. 399-411.

12. Moser, C. A. and Wolf Scott. British Towns. Edinburg: Oliver and Boyd, 1961.

13. Mumford, Lewis. The Culture of Cities. New York: Harcourt, 1938.

14. Nelson, Howard J. "A Service Classification of American Cities," Economic Geography, 31 (1955), pp. 189-210.

15. Ogburn, W. F. Social Characteristics of Cities. Chicago: International City Managers' Association, 1937.

16. Price, Daniel O. "Factor Analysis in the Study of Metropolitan Centers," Social Forces, 20 (1942), pp. 449-55.

17. Riemer, Svend. The Modern City. New York: Prentice-Hall, Inc., 1952.

18. Schnore, Leo F. "The Social and Economic Characteristics of American Suburbs," The Sociological Quarterly, 4 (1964), pp. 122-34.

19. Smith, R. H. T. "Method and Purpose in Functional Town Classification," Annals of the Association of American Geographers, 55 (1965), pp. 539-48.

20. Tarver, James D. "Suburbanization of Retail Trade in the Standard Metropolitan Areas of the United States, 1948-54," American Sociological Review, 22 (1957), pp. 427-33.

21. U.S. Bureau of the Census. Estimates of the Population of States with Components of Change, 1970 to 1973, Current Population Reports, Series P-25, no. 520 (1974).

22. Weller, Robert H. "Wife's Employment and Cumulative Family Size in the United States, 1970 and 1960." Demography, 14 (1977): 43-65. 